\section{Why us?}

There are many reasons why selling your practice to Colosseum Dental is a good idea for you, your patients and your staff.

First, we are keen to inspire clinical excellence among all our practice teams and we strive to provide the environment, facilities and professional training needed to achieve this. Second, we support the practice team in every way to encourage career development and the provision of exceptional dental care. We also encourage engagement from all individuals, we listen to ideas and we make changes accordingly.

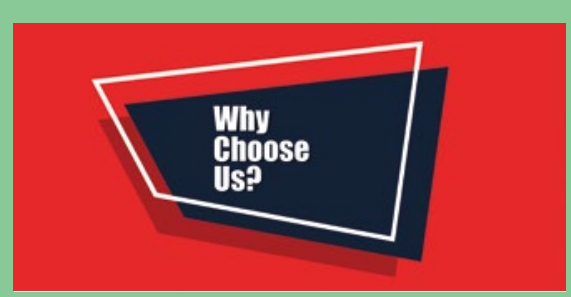

Third, we value the communities we operate in and are keen to be the best neighbour we can be.

If we sound like a good fit for you, why not find out more. For more information about Colosseum Dental visit www. colosseumdental.co.uk.

\title{
Brushes for every age
}

Children's home cleaning routines are more important than ever before. A great routine is regular and uses the right tools and products.

Premium oral hygiene brand Tandex produces high-quality brushes that are comfortable to hold and use.

Tandex has the perfect toothbrush for every patient, from babies to adults. For supervised brushing that won't be a trial, you can help parents select a brush that keeps their child's mouth clean, to start good habits early.

Keeping your youngest patients in good oral health will support their general health and wellbeing.

For more information on Tandex's range of products visit www.tandex.dk.

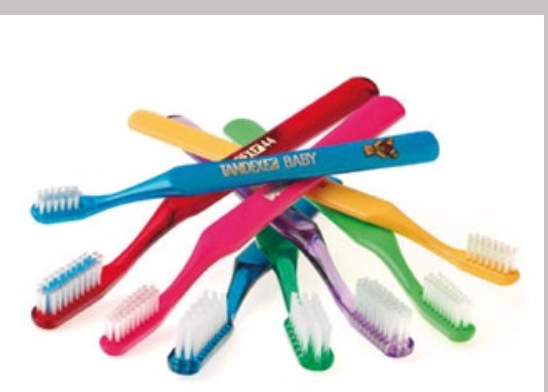

\section{Optimise post-surgical aftercare}

Help dental implant patients optimise their post-surgical aftercare routine by offering the new Perio Plus+ Regenerate mouth rinse.

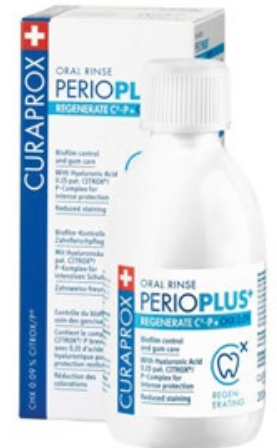

This contains the gold standard antiplaque agent, chlorhexidine, which has been naturally enhanced by combining it - a powerful anti-microbial, with CITROX anti-oxidant and anti-inflammatory substance extracted from bitter oranges. Perio Plus+ Regenerate also contains hyaluronic acid to promote optimal tissue renewal and accelerate the healing process.

Boasting a unique formula that is proven to be more effective than $\mathrm{CHX}$ alone at combatting plaque, Perio Plus+ Regenerate can support patients in protecting against peri-implant mucositis and peri-implantitis.

For more information call 01480862084 , email info@curaprox.co.uk or visit www.perioplus.com/uk.

\section{New solutions!}

J\&S Davis is delighted to bring you brand-new solutions available from leading manufacturer LM.

Following the

huge success of the

LM Dual Gracey designed for posterior indications, the LM Syntette Anterior instruments (available in standard and mini) provide a comprehensive solution for practitioners. Now you need only two instruments when you used to need four!

There are also two new additions to the LM-Arte instrument range, developed in collaboration with StyleItaliano. The LM-Arte Solo Posterior features one plugger end for bulk filling and composite material modelling, and one sharp end for contouring the occlusal surface anatomy. The LM-Arte Solo Anterior is designed for aesthetic anterior restorations, featuring rounded and straight spatulas for modelling anterior teeth, especially the labial surfaces.

For information on these and many other cutting-edge solutions from J\&S Davis, find out more by visiting www. js-davis.co.uk, calling 01438747344 or emailing jsdsales@js-davis.co.uk.

\section{Latex-free protection}

Did you know that professionals who routinely wear latex gloves are more likely to develop latex allergies in the future?

To combat this, Initial Medical has a huge array of gloves available for professionals, meaning that you need never worry about latex allergies again. Available in a wide selection of sizes and colours, the glove ranges from Initial Medical also include an expansive choice of materials, meaning that you can always find the perfect pair for all of your staff.

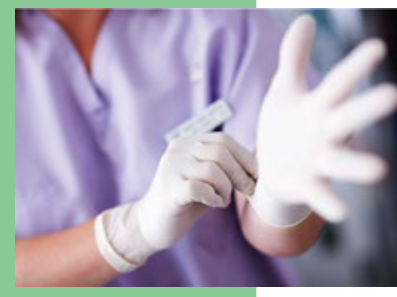

Prevent allergies and protect your hands by contacting Initial Medical on 0870850 4045 or visiting www.initial.co.uk/medical. 